\title{
Effect of cutting speed parameters on the surface roughness of Al5083 due to recrystallization
}

\author{
Elias Rezvani $^{1}$, Hamid Ghayour ${ }^{2}$, and Masoud Kasiri ${ }^{2}$ \\ ${ }^{1}$ Department of Mechanical Engineering, Faculty of Engineering, Najafabad Branch, Islamic Azad University, \\ Najafabad, Iran \\ ${ }^{2}$ Advanced Materials Research Center, Faculty of Materials Engineering, Najafabad Branch, Islamic Azad \\ University, Najafabad, lran \\ Correspondence to: Hamid Ghayour (ghayour_ham@iust.ac.ir)
}

Received: 16 October 2015 - Revised: 31 January 2016 - Accepted: 26 February 2016 - Published: 21 March 2016

\begin{abstract}
In the present study, the effect of machining parameters and recrystallization on surface quality of Al5083 has been investigated. In order to achieve minimum surface roughness of aluminum 5083 samples, statistical test design method of "full factorial" was used. In order to achieve the phenomenon of recrystallization, aluminum 5083 samples were set under $50 \%$ cold rolling mechanical operations. Then, the rolled samples were annealed for 2.5 to $240 \mathrm{~min}$ at $250^{\circ} \mathrm{C}$. The stress-strain curves were obtained from tensile tests. Then, dry machining was carried out on the original and crystallized samples under the same conditions. Results of surface roughness, tensile, and microstructure tests indicated the reduction of surface roughness in the crystallized sample.
\end{abstract}

\section{Introduction}

Aluminum alloys are widely used in aerospace, marine, and automotive industries as material for lightweight structures. In this regard, the hard alloy of aluminum 5083 is preferred due to its acceptable strength, good corrosion resistance and weld ability. Obviously, the development of the capacity of plasticity in this material will increase its potential fo $r$ these applications (Sukumar et al., 2014; CRTD, 1994). Surface roughness is one of the factors affecting the mechanical properties such as corrosion resistance, abrasion resistance, flexibility, fatigue behavior, etc. Therefore, it is one of the effective parameters that cannot be neglected in designing.

Figure 1 shows the fish bone diagram of the parameters affecting surface roughness (Routara et al., 2009).

A number of empirical studies have concentrated on the surface roughness of aluminum alloys. Kiswanto et al. (2014) carried out research on the impact of spindle speed, feedrate, and time of machining on surface roughness of aluminum 100 alloy by micro-milling operations. They concluded that surface roughness decreases by increasing the spindle speed, while it increases as the time of machining passes and the feed-rate increases (Kiswanto et al., 2014). Results of machining of aluminum alloys using designing test methods indicate that minimum surface roughness can be achieved by maximum cutting speed and minimal feedrate (Pinar, 2013; Wang and Chang, 2004; Tammineni and Yedula, 2014; Rawangwong et al., 2012, 2014). Clack et al. examined the surface roughness of Aluminum 6061-T8 using genetic algorithm. The practical results of this study were consistent with genetic algorithm (Colak et al., 2007). The optimization process of the aluminum surface roughness was examined in light of machining parameters (Sukumar et al., 2014, Arokiadass et al., 2011, Oktem et al., 2005; Nair and Govindan, 2013; Vakondios et al., 2012; Zhang et al., 2007). Mahesh and Rajesh (2014) carried out 27 experiments to optimize the parameter of $\mathrm{CNC}$ machining process on aluminum 7075-T6 alloy using Taguchi fuzzy logic (Mahesh and Rajesh, 2014). The results of high-speed milling on aluminum alloy shows that a minimum surface roughness can be achieved by maximum cutting speed and a minimum feed-rate, and that the cutting speed has the highest impact on the quality of surface (Wang et al., 2013; Xiuli et al., 2010). Premnath et al. (2012) carried out a study on the surface 


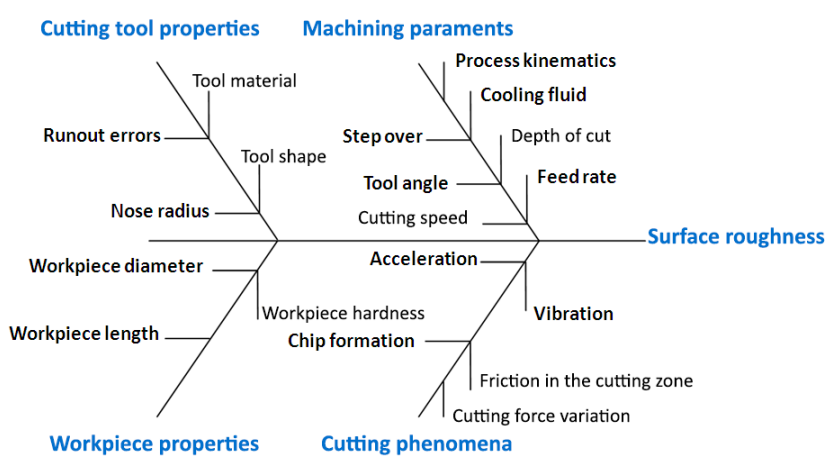

Figure 1. Fishbone diagram of the parameters that affect surface roughness [3].

roughness of combined aluminum surface by using predicted response of surface. The milling insert was tungsten carbide, and the variable parameters were rotational speed, and various compositions of aluminum (Premnath et al., 2012) Amran et al. did a study about the impact of machining parameters on the surface roughness of aluminum alloys during the drilling process. In their study, 20 tests were conducted with parameter variables including speed spindle, and drill diameter by surface response method (Amran et al., 2013). Kuttolamadom et al. (2010) studied the effect of feed-rate on the surface roughness of aluminum 6061 (Kuttolamadom et al., 2010). Lo et al. (2005) investigated the surface roughness of aluminum 6061 by three face-millings of various kinds by the Taguchi method and laser scattering. They finally concluded that high-speed steel face-mill had the best quality in terms of surface roughness (Lo et al., 2005).

Even though a large number of researches have been carried out on the parameters that affect surface roughness of Al5083 (Maeng et al., 2003), however, the simultaneous effect of recrystallization and cutting speed on surface roughness is still a challenge for researchers. Accordingly, this study aims to investigate the effect of machining and recrystallization parameters on Al5083 surface roughness. For this purpose, at first a series of tests were done on the aluminum 5083 sample to achieve optimal machining parameters for minimal surface roughness. Then, the effect of cutting speed on the surface roughness of crystallized aluminum 5083 sample was evaluated. Finally, the results of experiments were analyzed by using roughness measurement test, tensile measuring test, and also the images of microstructures.

\section{Materials and methods}

\subsection{Sample preparation and microstructural study}

Commercially available Al5083 plate with chemical composition as shown in Table 2 has been taken as the starting material in this research. For metallography and mic-

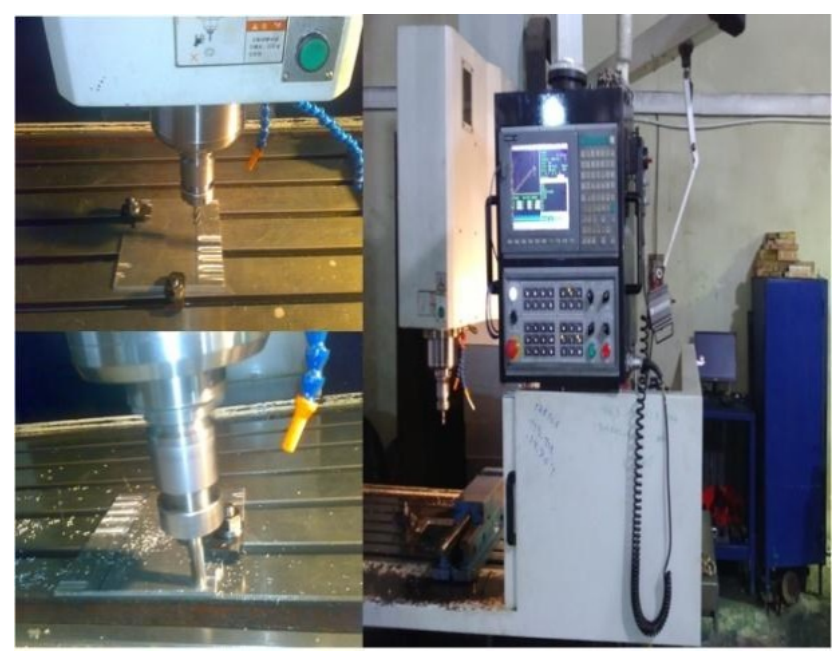

Figure 2. The CNC milling machine.

trostructural investigation, at first, samples with dimensions of $1 \mathrm{~cm} \times 1 \mathrm{~cm}$ were prepared by using the abrasive paper No. 100 to 2000 . Then the samples were polished with diamond and alumina powders. After polishing, all samples were etched in chemical solution containing $50 \mathrm{~mL}$ of Poulton's reagent was mixed with $25 \mathrm{~mL}$ of $\mathrm{HNO}_{3}$ and $40 \mathrm{~mL}$ of a composition of $3 \mathrm{~g}$ of chromic acid with $10 \mathrm{~mL}$ of water (Singh et al., 2013) for $1 \mathrm{~min}$.

In order to study microstructure, optical microscope (Model: Olympus) was employed.

\subsection{Mechanics of the cutting tool}

For the tensile test the designing of the samples was done based on the ASTM E8 standard by using Solid Works 2013 software, and the programming for machining was done by using Power Mill 10 software. Then, the three-axis NC milling machine (Syntec 10A model) with the maximum spindle speed of $9000 \mathrm{rpm}$, feed-rate of $10 \mathrm{~mm} \mathrm{~min}^{-1}$, $7.5 \mathrm{KW}$ motor drive, and Siemens control was used for machining the samples. Figure 2 shows the machine used in this study.

The tools used for dry machining included carbide tools coated with TiAIN (Seco model) with a diameter of $12 \mathrm{~mm}$, the tool tip radius of $0.8 \mathrm{~mm}$, and a spiral angle of $30^{\circ}$.

In this study, a similar tool was used for both experiments so that the tool wear parameter does not affect the results.

\subsection{Roughness and hardness measurements}

Many factors affect the machined surface roughness such as workpiece variables, tool variables and machining process variables. One example of workpiece variables is hardness, and some examples of tools variables include quality, tip radius and geometry of cutting. The cutting speed and depth of cutting are also regarded as machining variables ( $\mathrm{Li}$ and 
Table 1. Characteristics of roughness measurement machine.

\begin{tabular}{ll}
\hline Hommelwerke T8000 profilometer \\
\hline Pick-up type & TK300 \\
Measuring range & $80 \mu \mathrm{m}$ \\
Assessment length & $4.80 \mathrm{~mm}$ \\
Speed & $0.15 \mathrm{~mm} \mathrm{~s}^{-1}$ \\
Filter & M1 DIN 4777
\end{tabular}

Table 2. Chemical Composition of Al5083 (wt \%).

\begin{tabular}{ccccccc}
\hline $\mathrm{Al}$ & $\mathrm{Cu}$ & $\mathrm{Si}$ & $\mathrm{Fe}$ & $\mathrm{Cr}$ & $\mathrm{Mn}$ & $\mathrm{Mg}$ \\
\hline Bal. & 0.02 & 0.08 & 0.05 & 0.1 & 0.66 & 4.1 \\
\hline
\end{tabular}

Table 3. Parameters and levels of test.

\begin{tabular}{lllll}
\hline Factors & Unit & Level 1 & Level 2 & Level 3 \\
\hline Cutting speed & $\mathrm{m} \mathrm{min}^{-1}$ & 150 & 225 & 300 \\
Feed rate & $\mathrm{mm} \mathrm{min}^{-1}$ & 100 & 150 & 200 \\
Depth of cut & $\mathrm{mm}$ & 0.5 & 1 & 1.5 \\
\hline
\end{tabular}

Kishawy, 2006). In this study, in order to evaluate the surface roughness of the machined samples a roughness gauges device was used and its characteristics are given in Table 1. Hardness measuring was done by a universal hardness tester (uv1 model). At least three hardness measurements were done in each area and the average Rockwell B hardness was reported.

\subsection{Design of experiment}

In order to achieve a more accurate model of mutual impacts of three independent parameters of speed, feed-rate and depth of cutting on the dependent factor of surface roughness, full factorial experimental design was used. All the possible combinations of surface were considered, and the number of required tests equals the number of surfaces to the power of number of parameters $\left(3^{3}=27\right)$. One surface was also considered for each parameter. Table 3 shows the investigated parameters of the test. In addition, Minitab 16 software was used to examine the impacts of data.

\section{Results}

The results obtained from the average surface roughness in Table 4 indicate that plastic deformation was facilitated and the friction decreased with the increase of the cutting speed. As a result, the asperities and the filled edge of surface created by machining was reduced to a minimum and the surface roughness was reduced. The improvement in surface quality was obtained by maximum cutting speed of $300 \mathrm{~m} \mathrm{~min}^{-1}$. By increasing the feed-rate, the surface roughness increased so (a)

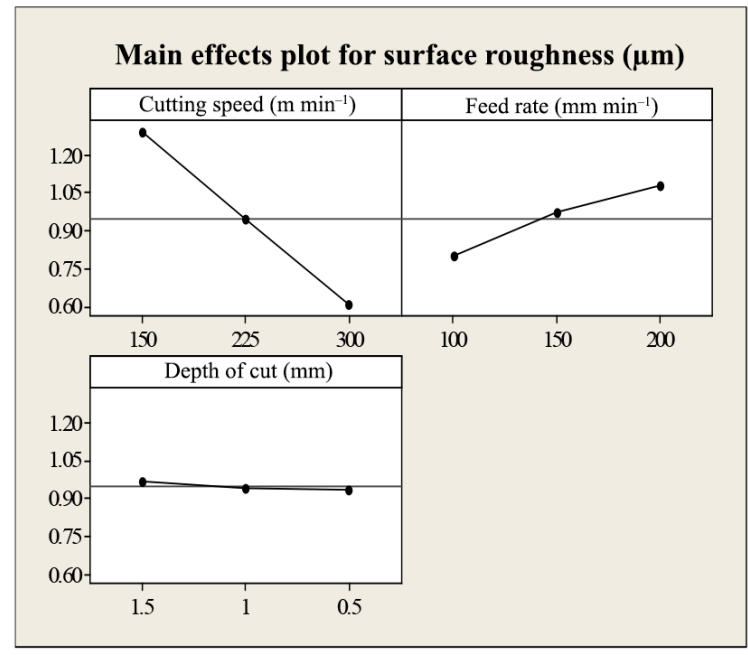

(b)

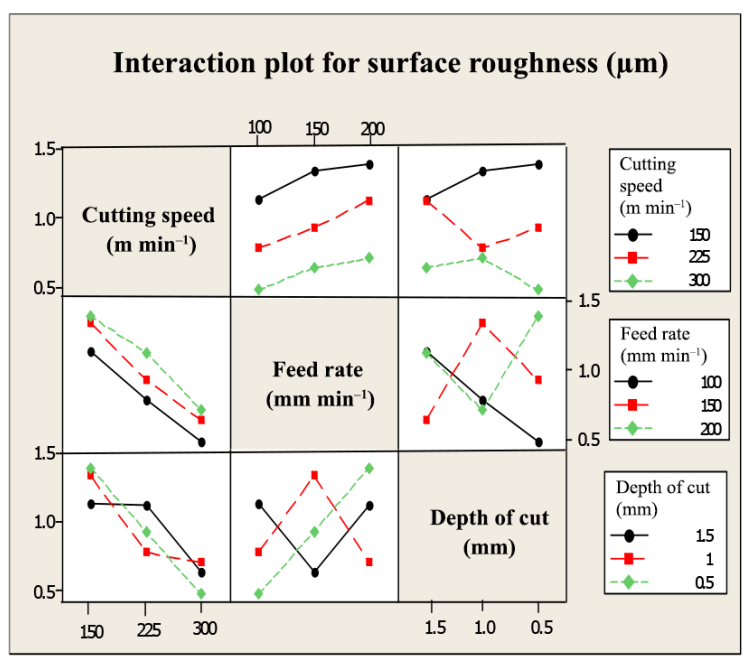

Figure 3. Individual parameters of machining affecting the surface quality: (a) main effects and (b) interactions.

that with the least feed-rate, i.e. $100 \mathrm{~mm} \mathrm{~min}^{-1}$, the best quality of the surface was achieved. Also the depth of cut had no regular impact on the surface roughness of aluminum sample but with the least cutting depth, i.e. $0.5 \mathrm{~mm}$, the best quality of surface was obtained. The average roughness for the original, rolled, and crystallized samples with different speeds is shown in Table 5.

\section{Discussion}

The main and mutual impacts of independent parameters on the surface roughness factor, which was designed by the Minitab 16 software, are shown in Fig. 3. As can be seen in this figure, cutting speed has the highest impact on surface roughness, which is due to the high difference in the height of points. Thus, by increasing of the cutting speed, the quality of surface roughness improved. As expected, with increasing of the feed-rate, the surface roughness increased and it was 
Table 4. The results of average surface roughness by full factorial method.

\begin{tabular}{|c|c|c|c|c|c|c|c|}
\hline $\begin{array}{l}\text { Trial } \\
\text { no. }\end{array}$ & $\begin{array}{c}\text { Cutting } \\
\text { speed } \\
\left(\mathrm{mm} \mathrm{min}^{-1}\right)\end{array}$ & $\begin{array}{c}\text { Feed rate } \\
\left(\mathrm{mm} \mathrm{min}^{-1}\right)\end{array}$ & $\begin{array}{l}\text { Depth of } \\
\text { cut }(\mathrm{mm})\end{array}$ & $\begin{array}{l}\mathrm{Ra} 1 \\
(\mu \mathrm{m})\end{array}$ & $\begin{array}{l}\mathrm{Ra} 2 \\
(\mu \mathrm{m})\end{array}$ & $\begin{array}{l}\mathrm{Ra} 3 \\
(\mu \mathrm{m})\end{array}$ & $\begin{array}{c}\text { Rmean } \\
(\mu \mathrm{m})\end{array}$ \\
\hline 1 & 150 & 100 & 0.5 & 0.98 & 1.07 & 0.95 & 1.00 \\
\hline 2 & 150 & 100 & 1 & 1.12 & 1.18 & 1.15 & 1.15 \\
\hline 3 & 150 & 100 & 1.5 & 1.34 & 1.24 & 1.26 & 1.28 \\
\hline 4 & 150 & 150 & 0.5 & 1.31 & 1.3 & 1.29 & 1.30 \\
\hline 5 & 150 & 150 & 1 & 1.34 & 1.39 & 1.29 & 1.34 \\
\hline 6 & 150 & 150 & 1.5 & 1.38 & 1.4 & 1.39 & 1.39 \\
\hline 7 & 150 & 200 & 0.5 & 1.36 & 1.35 & 1.40 & 1.37 \\
\hline 8 & 150 & 200 & 1 & 1.42 & 1.38 & 1.40 & 1.40 \\
\hline 9 & 150 & 200 & 1.5 & 1.41 & 1.37 & 1.51 & 1.43 \\
\hline 10 & 225 & 100 & 0.5 & 0.63 & 0.67 & 0.62 & 0.64 \\
\hline 11 & 225 & 100 & 1 & 0.77 & 0.81 & 0.85 & 0.81 \\
\hline 12 & 225 & 100 & 1.5 & 0.9 & 0.95 & 0.82 & 0.89 \\
\hline 13 & 225 & 150 & 0.5 & 0.83 & 0.88 & 0.84 & 0.85 \\
\hline 14 & 225 & 150 & 1 & 0.95 & 0.93 & 0.97 & 0.95 \\
\hline 15 & 225 & 150 & 1.5 & 0.99 & 1 & 0.98 & 0.99 \\
\hline 16 & 225 & 200 & 0.5 & 1.02 & 1.05 & 1.08 & 1.05 \\
\hline 17 & 225 & 200 & 1 & 1.11 & 1.15 & 1.07 & 1.11 \\
\hline 18 & 225 & 200 & 1.5 & 1.18 & 1.22 & 1.29 & 1.23 \\
\hline 19 & 300 & 100 & 0.5 & 0.42 & 0.37 & 0.44 & 0.41 \\
\hline 20 & 300 & 100 & 1 & 0.49 & 0.46 & 0.52 & 0.49 \\
\hline 21 & 300 & 100 & 1.5 & 0.5 & 0.54 & 0.55 & 0.52 \\
\hline 22 & 300 & 150 & 0.5 & 0.58 & 0.62 & 0.6 & 0.60 \\
\hline 23 & 300 & 150 & 1 & 0.58 & 0.6 & 0.56 & 0.58 \\
\hline 24 & 300 & 150 & 1.5 & 0.71 & 0.78 & 0.73 & 0.74 \\
\hline 25 & 300 & 200 & 0.5 & 0.66 & 0.65 & 0.64 & 0.65 \\
\hline 26 & 300 & 200 & 1 & 0.7 & 0.73 & 0.64 & 0.69 \\
\hline 27 & 300 & 200 & 1.5 & 0.72 & 0.83 & 0.79 & 0.78 \\
\hline
\end{tabular}

Table 5. The average roughness for the original, rolled, and crystallized samples with different speeds.

\begin{tabular}{lcccccccc}
\hline $\begin{array}{l}\text { Trial } \\
\text { no. }\end{array}$ & $\begin{array}{c}\text { Cutting } \\
\text { speed } \\
\left(\mathrm{m} \mathrm{min}^{-1}\right)\end{array}$ & $\begin{array}{c}\text { Feed rate } \\
\left(\mathrm{mm} \mathrm{min}^{-1}\right)\end{array}$ & $\begin{array}{c}\text { Depth of } \\
\text { cut }(\mathrm{mm})\end{array}$ & $\begin{array}{c}\mathrm{Ra}(\mu \mathrm{m}) \\
\text { without } \\
\text { rolled }\end{array}$ & $\begin{array}{c}\mathrm{Ra}(\mu \mathrm{m}) \\
50 \% \\
\text { rolled }\end{array}$ & $\begin{array}{c}\mathrm{Ra}(\mu \mathrm{m}) \\
\text { annealed } \\
\text { at } 250^{\circ} \mathrm{C} \\
\text { for } 10 \mathrm{~min}\end{array}$ & $\begin{array}{c}\mathrm{Ra}(\mu \mathrm{m}) \\
\text { annealed } \\
\text { at } 250^{\circ} \mathrm{C} \\
\text { for } 120 \mathrm{~min}\end{array}$ & $\begin{array}{c}\mathrm{Ra}(\mu \mathrm{m}) \\
\text { annealed } \\
\text { at } 250^{\circ} \mathrm{C} \\
\text { for } 240 \mathrm{~min}\end{array}$ \\
\hline 1 & 150 & 100 & 0.5 & 1 & 0.74 & 0.93 & 1.41 & 1.43 \\
2 & 225 & 100 & 0.5 & 0.64 & 0.44 & 0.59 & 1.11 & 1.08 \\
3 & 300 & 100 & 0.5 & 0.41 & 0.24 & 0.3 & 0.84 & 0.82 \\
\hline
\end{tabular}

observed that the depth of cutting has little effect on surface smoothness.

According to Fig. 4, high hardness (72 RB) is observed in the $50 \%$ cold-rolled sample due to the increased density of the sample. Hardness was reduced from min 2.5 to 5 , but an increase can be seen in hardness of the samples from min 5 to 10 : it increases from $55.87 \mathrm{RB}$ in the original sample to its maximum of $61.9 \mathrm{RB}$ after min 10 . The hardness of samples also decreased from min 10 to 240 .

Images of metallography in Fig. 5 show that the new coaxial grains are not formed in $\min 2.5$.
A decrease can be seen in the size of grains from min 5 to 10 , so that the size of grains reached to its minimum of 27 microns in min 10. The size of grains also increases from min 10 to 240 and finally reaches to 85 microns where it remains almost constant. Based on the results of hardness and metallographic images, recrystallization phenomenon occurred in min 10.

The reason for hardness variations can be explained in light of recrystallization phenomenon. After $50 \%$ cold working on the sample, due to dramatic increase in density of dislocations and also residual energy in the sample, the hardness 


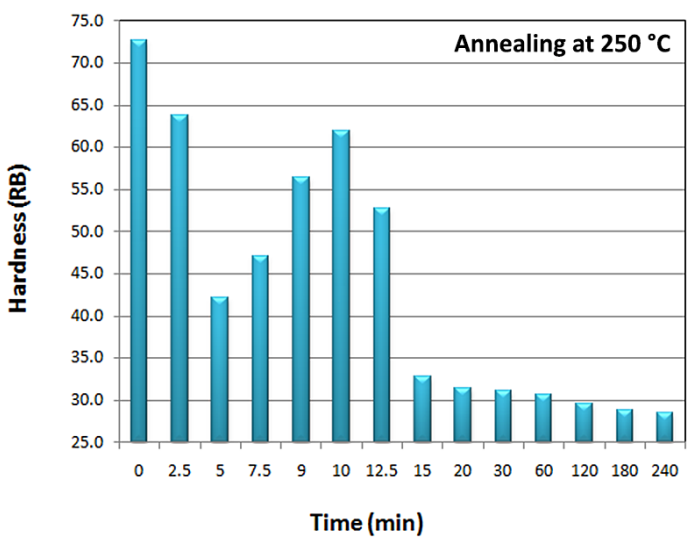

Figure 4. Hardness testing vs. annealing at $250{ }^{\circ} \mathrm{C}$ for the $50 \%$ cold rolled sample at different times.

value reaches $72 \mathrm{RB}$. After annealing at $250^{\circ} \mathrm{C}$ for $5 \mathrm{~min}$, the internal energy decreases. At the same time, the density of dislocations decreases as well, which leads to the reduction of hardness to about $42 \mathrm{RB}$. As can be seen from the figure displaying microstructure (Fig. 5a), at 5 min the new recrystallized grains have not been formed yet and the decrease of hardness is due to the decrease in density of dislocations. By increasing the annealing time to $10 \mathrm{~min}$, the sample hardness remarkably increases to $61.9 \mathrm{RB}$, which is due to the formation of recrystallized grains and decrease of grain size. According to Petch-Hall relation $\left(\sigma_{Y}=\sigma_{i}+K_{Y} / D^{1 / 2}\right)$, the strength and hardness increase as the grain size becomes smaller because the grain boundaries act as barriers against the movement of dislocations, hence leading to the rise of strength as well as hardness.

It is worth considering that in order for recrystallization to be initiated, a minimum cold work is required. The more the percentage of cold working, the higher the energy and the greater the number of formed grains. Also, the structure will be more fine-grained. In our study, the amount of cold work was $50 \%$. As can be seen in Fig. 5b, the fine recrystallized grains are formed. These grains are smaller compared to those in Fig. 5a.

With increase of the annealing time from 10 to $240 \mathrm{~min}$, the sample hardness dramatically declines to less than $30 \mathrm{RB}$, which is due to the extreme decrease of dislocations density and growth of recrystallized grains (Fig. $5 \mathrm{c}-\mathrm{g}$ ).

Dry machining was done under constant conditions for the samples annealed at $250^{\circ} \mathrm{C}$ similar to the original sample and with optimized parameters. By investigation of Fig. 6, it becomes clear that the minimal surface roughness can be seen in min 10 which is due to the recrystallization phenomenon. Surface roughness increases from min 10 to 240 and remains almost constant.

As can be seen in Fig. 7, in the $50 \%$ rolled sample, high strength and little strain can be observed. Due to the high strain and low strength, higher surface roughness is seen
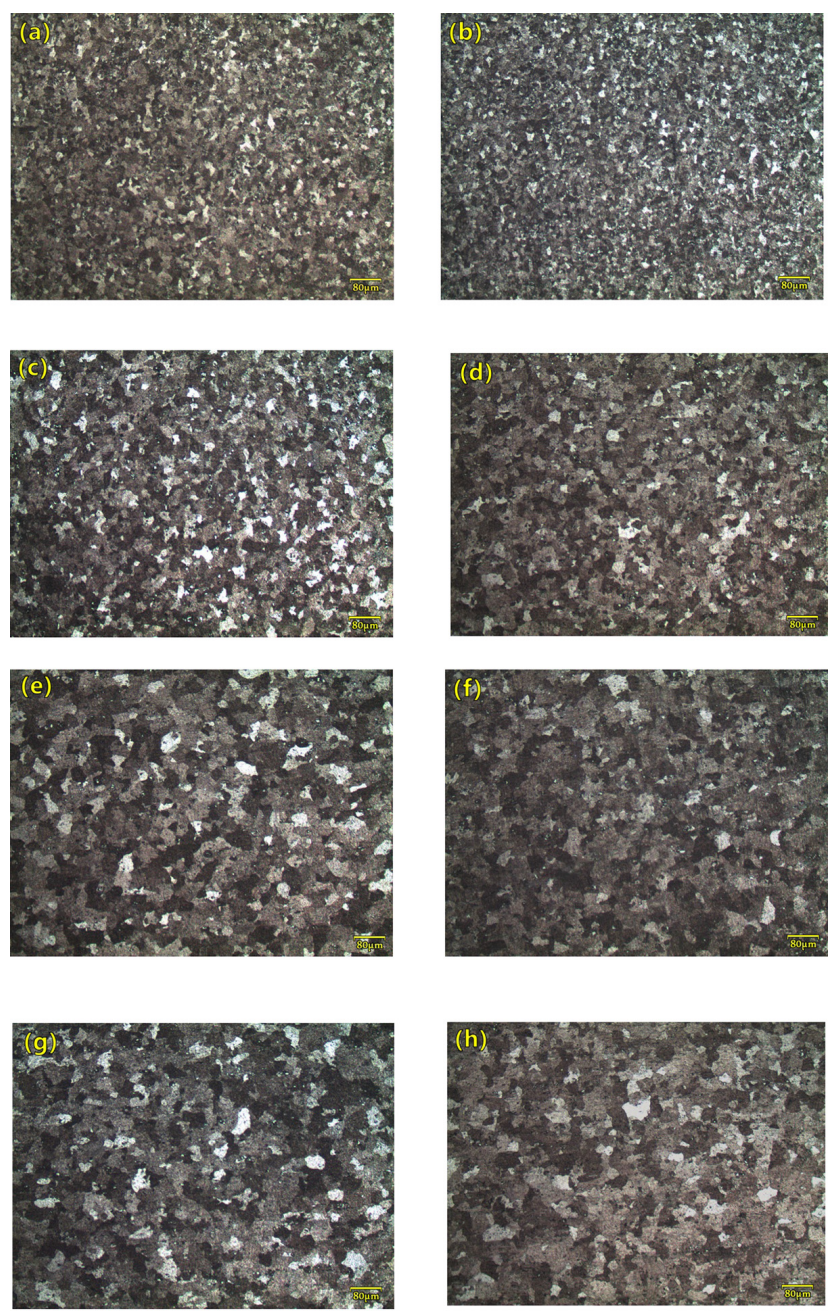

Figure 5. Metallographic samples annealed at $250^{\circ} \mathrm{C}$ at different times: (a) $5 \mathrm{~min}$, (b) $10 \mathrm{~min}$, (c) $15 \mathrm{~min}$, (d) $30 \mathrm{~min}$, (e) $60 \mathrm{~min}$, (f) $120 \mathrm{~min},(\mathrm{~g}) 180 \mathrm{~min}$ and (h) $240 \mathrm{~min}$.

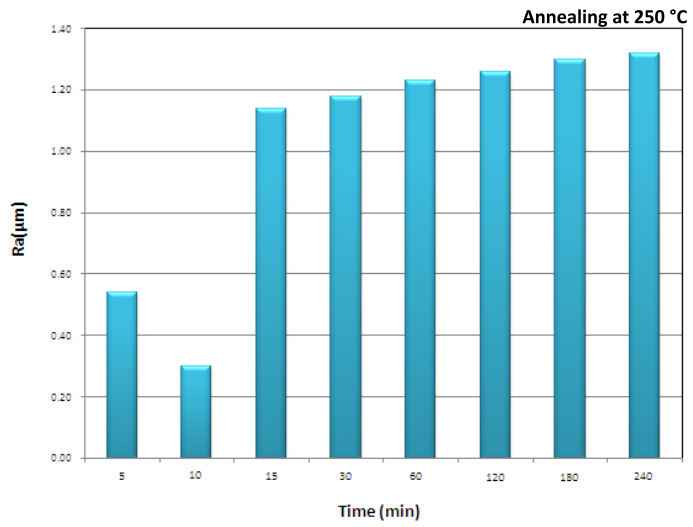

Figure 6. Surface roughness of the samples annealed at $250{ }^{\circ} \mathrm{C}$ at different times. 


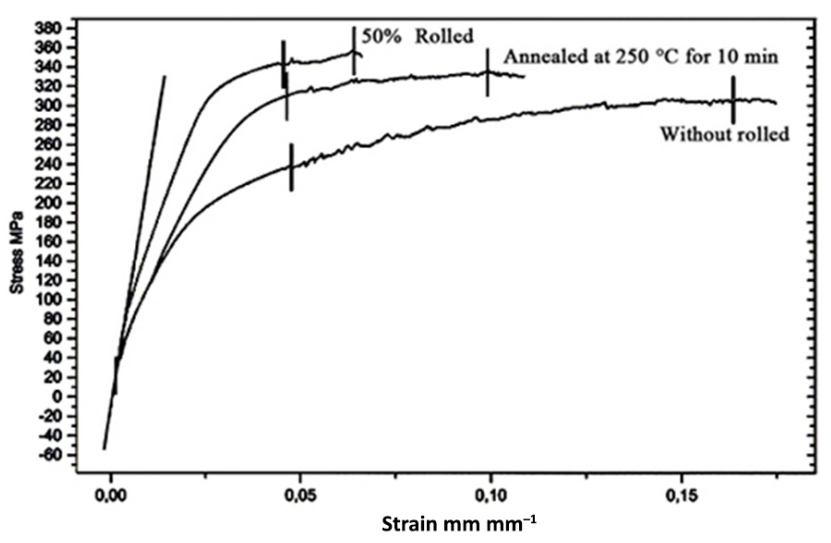

Figure 7. The strain-stress test for the original, crystallized, and $50 \%$ cold rolled samples.

in the original sample compared to the crystallized sample; however, better surface roughness is seen in the crystallized sample.

The machining was done on the crystallized samples with different cutting speeds and optimized parameters of feedrate and constant cutting depth. By comparison of roughness measurements in Table 5 it becomes clear that surface roughness decreases as the speed increases. In addition, by comparing roughness of the original sample with the crystallized one, it can be concluded that the surface roughness in the crystallized sample is less than the original sample due to the increase of hardness and the decrease in the grain size.

\section{Conclusions}

The effect of the parameters of the cutting speed, feed-rate and depth of cutting on the surface quality of aluminum 5083 was achieved by "full factorial" design method. Also, the effect of the cutting speed on the surface roughness of crystallized aluminum 5083 was investigated. The results of the analysis are as follows:

1. The minimum roughness ( 0.41 micron) was observed in experiment 19. From the results obtained from machining, it can be said that in order to reach an ideal surface roughness, maximum cutting speed $\left(300 \mathrm{~mm} \mathrm{~min}^{-1}\right)$, minimum feed-rate $\left(100 \mathrm{~mm} \mathrm{~min}^{-1}\right)$, and minimum cutting depth $(0.5 \mathrm{~mm})$ should be taken into consideration among the current machining parameters.

2. With $50 \%$ of cold working and annealing temperature of $250^{\circ} \mathrm{C}$, recrystallization starts at $10 \mathrm{~min}$.

3. In the recrystallized sample, because of minimum grain size and maximum hardness (61.9 RB), the best surface quality (i.e. minimum roughness: $0.41 \mu \mathrm{m}$ ) was achieved.
Acknowledgements. The authors are thankful to Islamic Azad University of Najafabad for help and support.

Edited by: T. Tawakoli

Reviewed by: M. Rashidzadeh and P. S. Schmalzried

\section{References}

Amran, M. A., Salmah, S., Hussein, N. I. S., Izamshah, R., Hadzley, M., Sivaraos, Kasim, M. S., and Sulaiman, M. A.: Effects of machine parameters on surface roughness using response surface method in drilling process, MITC, 18-20 November 2013, Malaysia, 2013.

Arokiadass, R., Palaniradja, K., and Alagumoorthi, N.: Surface roughness prediction model in end milling of $\mathrm{Al} / \mathrm{SiCP} \mathrm{MMC}$ by carbide tools, Int. J. Eng. Sci. Technol., 3, 78-87, 2011.

Colak, O., Kurbanoglu, C., and Kayacan, M. C.: Milling surface roughness prediction using evolutionary programming methods, Materials Design, 28, 657-666, 2007.

CRTD: Aluminium product applications in transportation and industry, ASME Centre for Research and Technology Development, 29 pp., 1994.

Kiswanto, G., Zariatin, D. L., and Ko, T. J.: The effect of spindle speed, feed-rate and machining time to the surface roughness and burr formation of Aluminium Alloy 1100 in micro-milling operation, J. Manufact. Process., 31, 231-242, 2014.

Kuttolamadom, M. A., Hamzehlouia, S., and Laine Mears, M.: Effect of Machining Feed on Surface Roughness in Cutting 6061 Aluminium, International Centre for Automotive Research, 2010.

Li, L. and Kishawy, H. Y.: A model for cutting forces generated during machining with self-propelled rotary tools, Int. J. Mach. Tools Manufact., 46, 1388-1394, 2006.

Lo, S. P., Chiu, J. T., and Lin, H. Y.: Rapid measurement of surface roughness for face-milling aluminium using laser scattering and the Taguchi method, Int. J. Adv. Manuf. Technol., 26, 10711077, 2005.

Maeng, D. Y., Lee, J. H., and Hong, S. I.: The effect of transition elements on the superplastic behavior of Al-Mg alloys, Mat. Sci. Eng., A357, 188-195, 2003.

Mahesh, T. P. and Rajesh, R.: Optimal Selection of process parameters in CNC end milling of Al 7075-T6 aluminium alloy using a Taguchi-Fuzzy approach, AMME, 27-29 May 2014, Egypt, 2014.

Nair, A. and Govindan, P.: Multiple Surface Roughness Characteristics Optimization in CNC End Milling of Aluminium using PCA, Int. J. Res. Mech. Eng. Technol., 3, 17-21, 2013.

Oktem, H., Erzurumlu, T., and Kurtaran, H.: Application of response surface methodology in the optimization of cutting conditions for surface roughness, J. Mater. Process. Technol., 170, 11-16, 2005.

Pinar, A. M.: Optimization of Process Parameters with Minimum Surface Roughness in the Pocket Machining of AA5083 Aluminium Alloy via Taguchi Method, Arab. J. Sci. Eng., 38, 705714, 2013.

Premnath, A. A., Alwarsamy, T., Abhinnav, T., and Krishnakant, C. A.: Surface Roughness Prediction by Response Surface Methodology in Milling of Hybrid Aluminium composites, Interna- 
tional Conference on Modelling Optimisation and Computing, 10-11 April 2012, Kumarakoil, 2012.

Rawangwong, S., Chatthong, J., Boonchouytan, W., and Burapa, R.: An Investigation of Optimum Cutting Conditions in Face Milling Aluminium Semi Solid 2024 Using Carbide Tool, 10th EMSES2012, 5-8 December 2012, Muang, Ubon-Ratchathani, Thailand, 2012.

Rawangwong, S., Chatthong, J., Boonchouytan, W., and Burapa, R.: Influence of Cutting Parameters in Face Milling Semi-Solid AA 7075 Using Carbide Tool Affected the Surface Roughness and Tool Wear, 11th EMSES2014, 21 December 2014, Thailand 2014.

Routara, B. C., Bandyopadhyay, A., and Sahoo, P.: Roughness modelling and optimization in CNC end milling using response surface method: effect of workpiece material variation, Int. J. Adv. Manuf. Technol., 40, 1166-1180, 2009.

Singh, D., Rao, P. N., and Jayaganthan, R.: Microstructures and impact toughness behavior of $\mathrm{Al} 5083$ alloy processed by cry rolling and afterwards annealing, Int. J. Miner. Metal. Mater., 20, 34-42, 2013.

Sukumar, M. S., Ramaiah, P. V., and Nagarjuna, A.: Optimization and Prediction of Parameters in Face Milling of Al-6061 Using Taguchi and ANN Approach, 12th GCMM, 8-10 December 2014, Vellore, India, 2014.
Tammineni, L. and Yedula, H. P. R.: Investigation of influence of milling parameters on surface roughness and flatness, Int. J. Adv. Eng. Technol., 6, 2416, 2014.

Vakondios, D., Kyratsis, P., Yaldiz, S., and Antoniadis, A.: Influence of milling strategy on the surface roughness in ball end milling of the aluminium alloy A17075-T6, Measurement, 45, 1480-1488, 2012.

Wang, M. Y. and Chang, H. Y.: Experimental study of surface roughness in slot end milling AL2014-T6, Int. J. Mach. Tools Manufact., 44, 51-57, 2004.

Wang, T., Xie, L. J., Wang, X. B., Jiao, L., Shen, J. W., Xu, H., and Nie, F. M.: Surface integrity of high speed milling of Al/SiC/65p aluminium matrix composites, 14th CIRP CMMO2013, 1314 June 2013, Turin, Italy, 2013.

Xiuli, F., Yongzhi, P., Yi, W., and Xing, A.: Research on Predictive Model Surface Roughness in High Speed Milling for Aluminium Alloy 7050-T7451, IEEE, 5-6 June 2010, Wuhan, 186189, 2010.

Zhang, J. Z., Chen, J. C., and Kirby, E. D.: Surface roughness optimization in an end-milling operation using the Taguchi design method, J. Mater. Process. Technol., 184, 233-239, 2007. 